\title{
Strategic Management and Financial Analysis in the Context of Epidemic -- A Case Study of Coca-Cola Company
}

\author{
Hongshan Geng ${ }^{1, \dagger}$, Nanyi Jiang ${ }^{2, \dagger}$, Qianwen Liang ${ }^{3, *, \dagger}$ \\ ${ }^{1}$ Business School, University of New South Wealth, Sydney, 2052, Australia \\ ${ }^{2}$ Henley Business School, University of Reading, Reading, RG6 6AH, UK \\ ${ }^{3}$ Kings Business School, Kings College London, London, WC2R 2LS, UK \\ ${ }^{*}$ Corresponding author. Email: k20058592@kcl.ac.uk \\ These authors contributed equally.
}

\begin{abstract}
The subject of this article is to analyze the financial statement and corporate strategy of Coca-Cola (referred to as KO) Company during the COVID 19 epidemic. The two main analysis methods are quantitative and qualitative analysis. The quantitative analysis uses ratios and Dupont to analyze Coca-Cola's ratio, looking at the impact of the epidemic on $\mathrm{KO}$ from the perspective of growth, profitability, liquidity, efficiency, and solvency. The qualitative analysis uses the SWOT and Porter five forces analysis method from the traditional accounting perspective to initially analyze the internal and external environment of Coca-Cola and uses the Balanced Score Card (BSC) from the management accounting perspective to interpret the advantages and disadvantages of the corporate strategy. The quantitative analysis results show that due to the epidemic's impact, KO's ability to repay debt and efficiency of using financial resources has been improved under the condition of the decline of KO's growth and profitability. But its finances and goodwill may suffer as a result of KO's acquisition problems. Qualitative analysis results show that KO's business processes are highly systematic, and strategic costs are reduced. In addition, the main risks of KO lie in the threat from competitors and the lack of innovation ability. Under the influence of the epidemic, its key profit indicators and debt ratio showed a negative trend. It failed to reach its financial target due to its special risk avoidance strategy of debt ratio. But it has excelled at attracting and retaining customers. This paper provides guidance and reference for future scholars to study KO's management and financial performance during the epidemic.
\end{abstract}

Keywords: COVID-19; Financial Statement Analysis; Qualitative Analysis ; Corporate Strategy; Coca-Cola

\section{INTRODUCTION}

Since the beginning of late 2019, the COVID-19 epidemic has swept across the globe, causing incalculable damage and millions of deaths. The impact of the spread of the virus has been twofold: firstly, the series of embargoes declared to prevent the spread of the epidemic has disrupted daily business and corporate activities, which has been very damaging to human resources; secondly, the severe health effects of COVID-19 on people have interfered with people's risk appetite for investment, turning them into risk-averse[1]. The COVID-19 epidemic, considered a "black swan event", affected various industries, including the food and soft drinks industry, where companies that were unable to respond in time lost out due to their dependence on the supply chain need for business continuity [2]. Coca-cola, a multinational soft drink company, has been experiencing a steady decline in performance since March 2020. Its US division is experiencing a $25 \%$ decline in sales from March to April, and the rest of its divisions are also being affected to varying degrees. In this situation, it is more important for management accountants and company CEOs to focus on strategic management shifts in the business [3] and think about changing strategies to meet the risk of a secondary epidemic rampage while seeking to ensure business continuity. 
There are two main perspectives on corporate strategy today: from a traditional financial accounting perspective, using models such as SWOT and Porter's Five Forces (P5F) combined with ratio analysis; or from a management accounting perspective, using the Balanced Scorecard (BSC) tool proposed by Norton and Kaplan (1986) to analyze performance and strategy components.

From a traditional financial perspective, both SWOT analysis and $\mathrm{P} 5 \mathrm{~F}$ have been extensively validated in practice. The SWOT being considered the most common tool for evaluating a company's marketing and strategy due to its simplicity, its $2 \times 2$ structure being able to be constructed quickly, and gaining a diversified perspective that helps to identify a company's internal strengths and weaknesses as well as its external environment [4]. In the application of SWOT, managers consider the company's image, efficiency, financial capacity, etc., to measure strengths and weaknesses. At the same time, the external analysis focuses on customers, competitors, market trends and opportunities, etc. Porter created P5F in the 1970s, which is an equally simple and influential tool that helps management analyse a company's current market attractiveness and market structure from the inside out [5]. Similarly, the application of the P5F has similarities to SWOT by analysing five micro-environmental capabilities that impact a company's profitability or industry competition for analysis and discussing the market structure before making strategic changes. But is the P5F established in the 1970s still applicable to the strategic analysis of modern large companies? Isabelle et al. (2020) [6], after a study, made a new adaptation of the $\mathrm{P} 5 \mathrm{~F}$ by introducing four new forces (level of innovation of competitors, exposure to globalisation, threats of digitalisation, industry exposure to regulated in/out-ofregulation activities) to the original framework and by this change, the P5F can better reflect the progressively globalised business of today's companies, enhancing the relevance of the $\mathrm{P} 5 \mathrm{~F}$ to corporate strategy and its comprehensiveness.

The Ratio analysis results are often used as a process to demonstrate the relationship between the various elements of a company's financial statements by presenting the financial results in the form of ratios or variables simply and understandably to external users. This type of analysis involves the collection, integration, and processing of management information. The results can be used to assess the current financial performance of a company and forecast the company's future vision [7]. In addition to traditional financial statement analysis models, there is the DuPont analysis, which breaks down the return on net assets due to multiplying the net asset margin with the equity multiplier. In contrast, the net asset margin is equal to the result of multiplying the net sales margin with the asset turnover ratio. Soliman (2008) [8] shows that the results of the DuPont analysis can be used to forecast future earnings and that focusing on the changes in the equity multiplier and asset turnover is useful for forecasting future trends using incremental accounting signals.

The role of the management accountant in strategic change is becoming more widely recognised by academics as the world is affected by 'black swan events [3]. From a strategic management accounting (SMA) perspective, a widely known tool for measuring corporate strategy and performance is the Balanced Scorecard (BSC) proposed by Norton and Kaplan (1986). It was the first time that performance management was implemented in four areas: users, internal processes, finance, learning, and innovation. In subsequent studies, Norton and Kaplan complemented the BSC framework by introducing two important analytical tools: the causeand-effect diagram and the strategy map, based on the core concept of BSC - cause-and-effect relationships $[9,10]$. The above two analytical tools are used to identify the causal links between the four dimensions of performance management and their critical success factors. The strategy map gives managers a clearer perspective by clearly identifying the incremental impact of business activities on the implementation of strategy and translating passive strategic objectives into proactive business behaviour [11].

The transformation of perspectives between traditional financial accounting to SMA lacks in existing theory. The combination of the two is clearly superior to pure financial analysis in the context of the epidemic. This paper takes Coca-cola as the subject of this study. It aims to discuss its strategy implementation in the context of the epidemic and the future direction of its transformation through the dual perspective of traditional financial analysis and management accounting in the context of the new crown. The research methodology will be a combination of qualitative and quantitative approaches, starting with a preliminary analysis of the internal and external problems of the company through SWOT and P5F to understand the current market structure and market attractiveness of Coca-cola. Then it analyzed the existing strategy and its current performance through key success factors analysis to analyse the strengths and weaknesses of the strategy itself. The aim is to analyse the strengths and weaknesses of the strategy itself. At the same time, the results of the Ratios and DuPont analyses are combined to quantitatively analyse Coca-cola's current strategy for the period 2018-2020 in together support the qualitative research with empirical research. 


\section{DATA AND METHODS}

\subsection{Data}

In terms of quantitative analysis of growth, this paper uses the net income and revenue data in the financial statements of Coca-Cola and PepsiCo from 2018 to 2020. It calculates two ratios for comparison, both of which are first-hand data. In terms of earnings, the two companies' profitability over three years is used, which is secondary data. We also use the receivable turnover rate from 2018 to 2020 of Coca-Cola and PepsiCo for comparison in terms of efficiency. The data are second-hand receivable turnover rate. In terms of liquidity, 3. Coca-Cola cash, marketable Securities, short-term investment, Total Current Assets, Total Current Assets, Long-term Debt data for the last three years is primary data. Regarding repayment ability, it also lists the changes of the Asset to total equity ratio of Coca-Cola and PepsiCo from 2018 to 2020, which is second-hand data. The above data is from the Coca Cola and PepsiCo websites

\subsubsection{Company introduction}

KO was founded on May 8, 1886, and headquartered in Atlanta, Georgia, USA. It is the world's largest beverage company, with $48 \%$ of the global market share and two of the world's top three beverages (Coca-Cola ranks. First, Pepsi ranks second, Coca-Cola has 160 beverage brands in 200 countries, including fizzy drinks, sports drinks, dairy drinks, juices, tea, and coffee. It also has a multi-industry trend, including buying Minute Maid to diversify into non-alcoholic drinks and investing in Costa coffee and milk.

At present (04.06.2021), the market value of CocaCola in the US stock market is 239.902 billion US dollars. Its biggest competitor is PepsiCo, which is similar to Coca-Cola in its products and its positioning in consumer groups and international positions.

\subsection{Method}

Quantitative and qualitative research methods are adopted in this paper. Quantitative research methods include Ratio analysis and DuPont analysis method; Qualitative research methods include SWOT and Porter's Five Forces.

\subsubsection{SWOT \& $P 5 F$}

SWOT is used in the qualitative analysis to conduct a preliminary analysis of KO's internal and external environment. The internal analysis includes strength and weakness, while external analysis includes opportunity and threat. The internal analysis aims to improve product quality and service, efficiency, operational and financial capabilities. In contrast, the external analysis focuses on international influence, market competition, industry trends, and other factors from outside the company.

$\mathrm{P} 5 \mathrm{~F}$ was also used in the qualitative analysis. P5F (including the threat of new entrants, the threat of substitution, bargaining power of buyers, bargaining power of suppliers, competitor rivalry) used five forces that determine the scale and degree of competition to analyze the industrial attraction and competitive strategy decision of $\mathrm{KO}$ in the epidemic situation.

\subsubsection{Ratio analysis \&DuPont analysis}

The ratio analysis method is an analysis method to analyze enterprises' financial status and operating results and understand the development prospects of enterprises through the ratio calculation of relevant indicators in financial statements. In this paper, the financial statement data of $\mathrm{KO}$ and PepsiCo are used to calculate the ratio analysis to conclude quantitative research.

${ }^{1}$ DuPont analysis method is also used in the quantitative analysis to comprehensively analyze the financial situation of an enterprise by using the relationship between several major financial ratios. It is a classic method used to evaluate the profitability of a company and the return on shareholders' equity and to evaluate the performance of an enterprise from a financial perspective [12].

\subsubsection{Ratio analysis formula}

Sales growth equals subtract the net sales of two periods divide the prior period sales.

The net income Growth formula subtracts the net income of two-period divide prior period profit.

Gross Profit Margin (=(total revenue - COGS) / the difference by total revenue).....[12]

Operating $\quad$ Profit $\quad$ Margin
earnings/revenue .............................. $[12]$

Net Profit Margin $=$ net profit $/$ total revenue * $100 \%$ [12]

The accounts receivable turnover ratio (= net credit sales / average accounts receivable) is an accounting metric used to quantify the effectiveness of a company in collecting its accounts receivable or money owed by customers [12]. 
Total Asset turnover rate (= net sales / average total assets) is an important indicator for evaluating the efficiency of enterprise asset management. Specifically, the asset turnover rate can be used to indicate the efficiency of a company's use of its assets to generate income [12].

\section{RESULT AND DISCUSSION}

This paper uses quantitative and qualitative research methods, starting with quantitative indicator analysis to analyse its growth, profitability, liquidity, solvency, and debt leverage. Then, the qualitative analysis section of this paper aims to analyse KO's internal and external environment, first using a SWOT analysis to initially identify the four factors that exist internally and externally. Then it applies the five capabilities in the P5F to analyse its threats and strengths, refining the risks and opportunities faced by KO. Finally, it conducts a BSCbased critical success factor analysis of $\mathrm{KO}$ to point out why its strategy has been successfully implemented.

\subsection{Quantitative Analysis}

Before doing ratio analysis, it is necessary to first look at the significant changes in KO's financial apartment from 2018 to 2020 .

Firstly, the policies in $\mathrm{KO}$ require that revenue should be recognized when the performance obligation is satisfied, which is regular. However, it also requires the company to recognize revenue in a 'faithful' depiction amount rather than the actual amount [13], which means that there are spaces for the company to adjust.

Secondly, KO would do goodwill and intangible assets impairment tests annually. If the fair value is less than the carrying amount, goodwill would be written down. The amount written down would equal the amount bigger than the carrying amount. In the financial statements that ended December 31, 2020, KO's goodwill in 2020 was $\$ 17,506$ million. Compared to the goodwill value of $\$ 16,764$ million in 2019 , there is a significant increase; However, there is no mention in the footnote related to the amortization of goodwill in the previous fiscal year. From the research by researchers, the growth of goodwill can be caused by two acquisitions in 2020, when the company acquired Fairlife, LLC, with a total market value of $\$ 1,052$ million.

With those policies and acquisitions, in the next part of the research, the ratio trend of the $\mathrm{KO}$ would be shown in five perspectives: growth perspective, profitability perspective, liquidity perspective, efficiency perspective, and solvency perspective.

\subsubsection{Growth \& Profitability \& Efficiency Perspectives}

Firstly, from the growth perspective, net income is an important source of data. In the income statement of $\mathrm{KO}$, it is clear that the net income increased from $\$ 6.5$ billion to about $\$ 9$ billion in 2019 and then dropped to $\$ 7.8$ billion in 2020. Accordingly, the net income growth rate first increased from $22 \%$ to $31.14 \%$ and then decreased to a negative $9.61 \%$ in 2020 . Furthermore, the sales growth rate also shows the status of KO's growth. The total sales growth trend is negative, and the growth in 2020 is actually negative $(-11.41 \%)$. Compared with Pepsi's stable increase in revenue and sales growth in Table 2, Coca-Cola has a huge jump during the COVID period (Table 1). Although the growing trend was much better than Pepsi before 2020, Coca-Cola is more seriously influenced by the pandemic and stops growing in sales and net income.

Table 1. KO's Data in Growth Perspective

\begin{tabular}{cccc}
\hline & $\mathbf{2 0 1 8}$ & $\mathbf{2 0 1 9}$ & $\mathbf{2 0 2 0}$ \\
\hline Net Income & $\$ 6476$ million & $\$ 8985$ million & $\$ 7768$ million \\
Revenue & $\$ 34300$ million & $\$ 37266$ million & $\$ 33014$ million \\
Net Income Growth Rate & $22.00 \%$ & $31.14 \%$ & $-9.61 \%$ \\
Sales Growth Rate & $-3.13 \%$ & $8.65 \%$ & $-11.41 \%$ \\
\hline Table 2. Pepsi's Data in Growth Perspective & \\
\hline Net Income & $\mathbf{2 0 1 8}$ & $\mathbf{2 0 1 9}$ & $\$ 7175$ million \\
Revenue & $\$ 12559$ million & $\$ 7353$ million & $\$ 70372$ million \\
Net Income Growth & $\$ 64661$ million & $\$ 67161$ million & $-2.61 \%$ \\
Rate & $-4.30 \%$ & $1.34 \%$ & $4.78 \%$ \\
Sales Growth Rate & $1.79 \%$ & $3.87 \%$ & \\
\hline
\end{tabular}


Secondly, profitability is also a perspective emphasized by both managers, investors, and shareholders. Since the revenue of KO decreased in the past three years, the operating profit margin increased from $21.82 \%$ to $29.01 \%$. Furthermore, the gross profit in the income statement also decreased in the past three years from $\$ 21.2$ billion to $\$ 19.6$ billion. Accordingly, the net profit margin increased from $23.98 \%$ to $29.53 \%$. Moreover, the changing trend in Coca-Cola and Pepsi is completely different in Table 3 . The different services could cause the researchers' perspective ranges between Coca-Cola and Pepsi. Coca-Cola is more focused on the soft drink industry; However, Pepsi also pays attention to the snacks and deliverable catering industry. During the pandemic, people could improve their need for both snacks and soft drinks. Still, the profitability can be hurt by the increasing raw material cost and the difficulty of production. The additional profitable activities bring more opportunities to Pepsi, making it perform better than Coca-Cola and keep growing in the pandemic market.

Thirdly, the researcher mainly discussed the ratio from an efficiency perspective, which is the receivable turnover rate. Coca-Cola has a higher receivable turnover rate than Pepsi (Table 4), which shows its better management in customer quality and the lower risk in liquidity.

Table 3. Different Trend of ROE in KO and Pepsi

\begin{tabular}{ccc}
\hline & KO & Pepsi \\
\hline $\mathbf{2 0 1 8}$ & $48.31 \%$ & $71.84 \%$ \\
$\mathbf{2 0 1 9}$ & $59.99 \%$ & $63.62 \%$ \\
$\mathbf{2 0 2 0}$ & $50.94 \%$ & $63.82 \%$ \\
\hline
\end{tabular}

Table 4. Receivable Turnover Rate in KO and Pepsi

\begin{tabular}{cccc}
\hline & $\mathbf{2 0 1 8}$ & $\mathbf{2 0 1 9}$ & $\mathbf{2 0 2 0}$ \\
\hline KO's Receivable Turnover Rate & 9.33 & 9.74 & 9.28 \\
Pepsi's Receivable Turnover Rate & 9.13 & 8.98 & 8.67 \\
\hline
\end{tabular}

Table 5. KO's Balance Sheet Liquidity Data

\begin{tabular}{cccc}
\hline & $\mathbf{2 0 1 8}$ & $\mathbf{2 0 1 9}$ & $\mathbf{2 0 2 0}$ \\
(\$ in million) & (\$ in million) & (\$ in million) \\
\hline Cash & 8926 & 6480 & 6795 \\
Marketable Securities & 5013 & 3228 & 2348 \\
Short-term investment & 2025 & 1467 & 1771 \\
Total Current Asset & 30634 & 20411 & 19240 \\
Total Current Liability & 29223 & 26973 & 14601 \\
Long-term Debt & 25364 & 27516 & 40125 \\
\hline
\end{tabular}

Table 6. Total Assets-to-Total Equity Ratio in KO and Pepsi

\begin{tabular}{rccc}
\hline & $\mathbf{2 0 1 8}$ & $\mathbf{2 0 1 9}$ & $\mathbf{2 0 2 0}$ \\
\hline KO's Total Assets-to-Total Equity Ratio & 4.37 & 4.09 & 4.10 \\
Pepsi's Total Assets-to-Total Equity Ratio & 5.32 & 5.28 & 6.85 \\
\hline
\end{tabular}




\subsubsection{Liquidity Perspective}

In the balance sheet of $\mathrm{KO}$, there is a decreasing trend in cash, marketable security, short-term investment, and so on, so the total current asset has decreased significantly. Furthermore, the current liability also decreased from $\$ 29.2$ billion to $\$ 14.6$ billion. The company changes its financial structure and now has more long-term debts than before. With this background, the current ratio and quick ratio, which are based on current assets and current liability, increased significantly. This shows that the company tried to improve its ability to pay off debts in the short term to face the unstable market affected by the pandemic. This shows that $\mathrm{KO}$ has an attitude of risk aversion. Its strategy would focus more on how to get through the risk period smoothly.

\subsubsection{Solvency Perspective}

Although the liquidity risk of Coca-Cola is not very urgent, its performance from a solvency perspective is not good enough. Coca-Cola has not changed its financial structure enough during the pandemic. Debts still take a great proportion in Coca-Cola's financing structure, which would lead to solvency risk in the unstable market. However, Pepsi as the main competitor of Coca-Cola, has an even worse solvency status. It has a higher Total assets-to-Total equity ratio, which shows great challenges from a solvency perspective.

Finally, researchers use Dupont analysis to show KO's attitude toward risk in the past three years. According to the research in 2014 (Bauman), the change of asset turnover rate is connected with return on net operating assets, and profit margin changing direction would also influence future return on net operating assets. From the data in ratio analysis, it is clear that the net profit margin of $\mathrm{KO}$ has increased from $23.98 \%$ to $29.53 \%$. This positive trend shows that return on net operating assets would increase in the future, and it also shows that $\mathrm{KO}$ has an efficient cost structure. Moreover, the decrease leverage ratio from 4.89 to 4.56 shows that $\mathrm{KO}$ prefers to avoid risk as much as possible, which is different from the risk strategy before the pandemic. KO is now more sensitive to risks because of the growing uncertainty in the pandemic. Moreover, the decrease of asset turnover rate from $41 \%$ to $38 \%$ shows that the use of capital is not efficient enough, which can be the result of narrow concentration on unhealthy soft-drink (Hao, Choi 2019). KO's plan of acquisition would solve this problem in the future since more profitable activities related to healthy drinks would be considered after acquisition. Furthermore, the Dupont analysis also shows that $\mathrm{KO}$ is improving its ability to pay off a short-term debt to overcome unpredictable risks in the future.

\subsection{Qualitative analysis}

\subsubsection{SWOT analysis}

This SWOT analysis was conducted based on the current situation of Coca-cola (KO), which is described below in terms of strengths, weaknesses, opportunities, and threats.

KO's product appeal and internal business processes analysis shows that $\mathrm{KO}$ has the following strengths and weaknesses. Firstly, KO has been the market leader in carbonated soft drinks (CSD) since 2004, with a market share of $42.5 \%$ at one point in 2015 . Secondly, KO holds a confidential formula and has worked for many years to introduce new flavours. Also, it has expanded its business from carbonated soft drinks to include non-alcoholic beverages such as juice, coffee, and milk through acquisitions of companies such as Juice Source, COSTA, and Fairlfe. Thirdly, KO excels at marketing. In the 2020 Global Brand Footprint published by Cato, KO was chosen by consumers worldwide more than six billion times, ranking first on the list, which is not unrelated to its overwhelming global advertising. Fourthly, KO compresses costs through front-to-back integration. The Group controls raw material plantations, minerals, bottle makers and bottlers, and assembly lines from production to distribution, imposing maximum limits on costs. However, KO's products and the company's weaknesses are obvious, the first being the impact of the idea that carbonated beverages are not good for health, and secondly, the lack of room for innovation in KO's main business, which further contributes to the company's slow growth rate.

There are still opportunities and threats in the market. For KO's main product, carbonated beverages, the recently launched "diet coke" aligns with the health concept. The broadened business scope has given KO a new competitive edge in the industry. The relatively small number of competitors of the same size, such as Pepsi and Nestlé, can still threaten KO, as their products are highly similar in price and taste to KO's products, posing a substitution risk. In addition, because of the impact of the global embargo brought about by COVID19, which affects raw materials, human resources, and business processes, it is a major threat to companies like $\mathrm{KO}$ that rely on multinational operations. 


\subsubsection{Five force}

Based on SWOT analysis, this P5F analysis has been conducted for $\mathrm{KO}$ to give more detail to the internal and external view.

- The weak threat of new entrants

Thanks to KO's superior cost control business processes, which create cost barriers to entry in the soft drinks industry, its market leader status and visibility mean that it is less threatened by new entrants.

\section{- Moderate threat of substitution}

KO specialises in non-alcoholic beverages, and there are substitutes in the industry, represented by Pepsi and Nescafe, with similar prices and flavours.

\section{- Medium bargaining power of buyers}

Due to KO's strong backward integration process, the directly relevant buyers are consumers and distributors such as supermarkets. It has a highly sticky user base, but at the same time, the switching costs of buyers are low, and the bargaining power of distributors (e.g., supermarkets, etc.) is greater than that of consumers.

\section{- Weak bargaining power of suppliers}

KO has raw material production and processing industries such as minerals and plantations. Due to its large intake volumes and forward integration processes, suppliers are highly dependent on $\mathrm{KO}$ and have high switching costs resulting in weak bargaining power.

\section{- Strong competitor rivalry}

Pepsi is KO's main competitor in the soft drinks industry, and the company poses risks for $\mathrm{KO}$, such as the threat of substitutes. As of May 2020, its market capitalisation of $\$ 188.6$ billion has surpassed KO's by almost $\$ 5$ billion, and its ability to innovate and scope of business is stronger than KO's, so the competitor's capabilities should not be underestimated.

\subsubsection{Key success factor identification based on the $B S C$ perspective}

In this section, the critical success factors are analysed on four levels: finance, internal processes, learning and innovation, and customers to identify existing strengths and weaknesses.

In terms of financial processes, the company has a complete valuation model. It can operate electronically, except for revenue recognition, where there is a lack of clarity in the accounting for the processing of returns. In terms of cost control, implementing a cost minimisation strategy is an essential part of the success factor in conjunction with its integrated backward and forward operations and the results of section 4 of this paper. In addition, in terms of creating value for customers, KO's sustainability and social contribution and water conservation projects have added value to the products themselves, gaining goodwill and increasing its revenue.

In terms of internal processes, the company's strength lies in its simple and linear processes, making it easy to implement strategies and for employees to understand them. From the control of raw materials to the confirmation of distribution, the process is systematic and truly streamlined. In terms of work atmosphere control, a diverse work atmosphere is promoted through the organisation of numerous communications, etc. In terms of supervision, $\mathrm{KO}$ has an independent internal audit department, clear regulations between the board of directors, and a fair distribution of responsibilities, which provides good management of the company's internal controls.

In terms of learning and innovation, $\mathrm{KO}$ has an employee training process and training and dialogue on various aspects such as racial equality and women's rights, intending to increase employee satisfaction. In terms of innovation, $\mathrm{KO}$ is a little weaker in terms of drinks but has introduced and made extensive use of environmentally friendly, renewable plastics in the materials used in its bottles.

Customer satisfaction is already reflected at the top of the Global Brand Footprint 2020 list, and its means of acquiring new customers is mainly through massive advertising everywhere and on various social platforms. For this aspect of customer retention, KO is slightly weaker, especially in the epidemic context, where sales continue to decline. However, to retain customers and meet the health key, KO has acquired a more healthconscious beverage industry such as Fairlife and launched Diet coke, which contains less sugar than Pepsi and better meets the company's strategic objectives.

\subsection{Discussion}

The result of quantitative analysis is that $\mathrm{KO}$ is having difficulty during the pandemic. The growth and profitability of the company slow down because of the pandemic. The change of financial structure shows the liquidity and solvency issues of the company. Although there are some changes to improve the ability to pay off short-term debt, KO still relies too much on debts. Furthermore, the acquisition during the past 3 years brings an increase in goodwill and other intangible assets. It is highly possible that the goodwill would write-off in the foreseen future, which would negatively affect KO's financial performance. Moreover, $\mathrm{KO}$ has a good performance in customer management and efficiency in using financial resources. Its high receivable turnover rate would decrease the pressure from customers' negative 
performance. With this advantage, KO can be more efficient than other competitors who have worse customer management and take a bigger market proportion. With the analysis in different operating regions, combined with the current situation in pandemic control, the researchers would suggest $\mathrm{KO}$ take more effort on developing markets in Asia Pandemic, especially China. Since the market in east Asia has been on the way to recovery, $\mathrm{KO}$ can develop more profitable activities than in the hardest hit by the epidemic, such as North America and Southeast Asia.

The qualitative study results show that the cost control component of KO's existing strategy has been implemented more successfully. It has highly systematic business processes within the company, and that its products are highly competitive in the market but lack substitutability. The SWOT and P5F studies show that KO's main risks are the slow growth rate due to the threat of substitutes and the lack of innovation capacity, and the conflict with competitors. And based on the management perspective, combined with the ratio analysis results, its financial performance, although it has complete control over its processes, shows a negative trend in its key profitability indicators and debt ratios. On the one hand, KO has been affected by the epidemic and the impact of its health philosophy leading to a decline in its earnings. On the other hand, as reflected through its financial leverage ratio, the debt ratio has shifted to a risk-averse strategy after the epidemic, resulting in its financial perspective falling short of financial targets. The performance of its internal processes mainly monitors its inventory turnover and cost management strategy, which, upon examination, $\mathrm{KO}$ has good control over, excluding the epidemic risk. $\mathrm{KO}$ also demonstrates its popularity in terms of customer retention and learning innovation, achieving good customer attraction and retention.

\section{CONCLUSION}

In this research, quantitative and qualitative analyses are used to provide more useful information to managers and other investors. In the quantitative analysis, researchers firstly introduce the special changes that happened in the research period. Then, ratio analysis shows trends in growth, profitability, efficiency, liquidity, and solvency perspectives. The general trend of the company in the past three years is that it is greatly affected by COVID-19 but still has a chance to recover from this crisis. DuPont analysis is also used to show how the financial structure should be changed if the company wants to reduce risk in the foreseen future. In qualitative analysis, SWOT, Porter's Five Forces, and a balanced scorecard are used to illustrate the internal and external conditions of the company. Furthermore, managers can make adjustments according to the major problem of the company and the company's strengths and weaknesses. In conclusion, the combination of management accounting and strategic management can support the company better in the unpredicted risks by efficient changes in both operation and strategies. When the external environment is becoming riskier according to the results of the management accounting method, and the quantitative analysis shows negative trends in the company's liquidity and solvency perspective, it is recommended to make adjustments in company strategies. If the company is risk aversion, managers should pay attention to the liquidity and solvency ratios included in the Dupont analysis. With the improvement of short-term pay-off ability, the company would be safer in the risky and competitive market than in high leverage situation. However, it is less financially efficient than before.

\section{REFERENCES}

[1] Ozili, P. and Arun, T., 2020. Spillover of COVID-19: Impact on the Global Economy. SSRN Electronic Journal, p.27.

[2] Reid, G., O'Beirne, N. and Gibson, N., 2020. How companies can reshape results and plan for a COVID-19 recovery. [online] EY. [Accessed 19 May 2021].

[3] Thomson, J., 2021. How Management Accountants Mitigate Risk In An Uncertain World. [online] Forbes. [Accessed 20 May 2021].

[4] Helms, M. and Nixon, J., 2010. Exploring SWOT analysis - where are we now? Journal of Strategy and Management, 3(3), pp.215-251.

[5] Dälken, F., 2014. Are Porter's five competitive forces still applicable? A critical examination concerning the relevance for today's business. bachelor. University of Twente.

[6] Isabelle, D., Horak, K., McKinnon, S. and Palumbo, C., 2020. Is Porter's Five Forces Framework Still Relevant? A study of the capital/labour intensity continuum via mining and IT industries. Technology Innovation Management Review, 10(6), pp.28-41.

[7] Babalola, Y. and Abiola, F., 2013. Financial ratio analysis of firms: A tool for decision making. International Journal of Management Sciences, 1(4), pp.132-137.

[8] Soliman, M., 2008. The Use of DuPont Analysis by Market Participants. The Accounting Review, 83(3), pp.823-853. 
[9] Kaplan, R.S. \& Norton, D.P. 2001, "Transforming the Balanced Scorecard from Performance Measurement to Strategic Management: Part II", Accounting horizons, vol. 15, no. 2, pp. 147-160.

[10] Kaplan, S.E. \& Wisner, P.S. 2009, "The Judgmental Effects of Management Communications and a Fifth Balanced Scorecard Category on Performance Evaluation", Behavioral research in accounting, vol. 21, no. 2, pp. 37-56.
[11] Rompho, N., 2012. An experiment in the usefulness of a strategy map. Measuring Business Excellence, 16(2), pp.55-69.

[12] Referenced from Wikipedia. (Accessed 4th June 2021)

[13] Coca-Cola 2021, The Coca-Cola System, Coca-Cola [Accessed 21 March 2021]. 